\title{
Metateoria e Diplomática: a construção de um novo modelo de análise para a identificação de documentos de arquivo
}

Metateoría y diplomática: la construcción de un nuevo modelo de análisis para la identificación de los documentos de archivo

Metatheory and Diplomatics: building a new model of analysis for the identification of archival records

\author{
Natália Bolfarini ToGNOLI \\ Faculdade de Filosofia e Ciências - UNESP, Av. Hygino Muzzi Filho, 737 Marília - São Paulo - Brasil - CEP: 17525-900, \\ nataliabtognoli@yahoo.com.br
}

\begin{abstract}
Resumen
Desde la década de los años 80, la Archivística se ha enfrentado a nuevos desafíos en lo que respecta a la organización del conocimiento archivístico. En este sentido, emerge el concepto de identificación, como parte del proceso de gestión documental. Este proceso cuenta con los estudios de la diplomática contemporánea, ya que busca la comprensión del contexto de producción por medio del análisis documental ofrecido por el análisis diplomático. En este sentido, el presente artículo presenta un nuevo modelo para la identificación de los documentos de archivo, con base en los métodos diplomáticos desarrollados en los siglos XVII, XIX y XX. Para eso, se contó con la metateoría como metodología para el conocimiento y análisis de los métodos diplomáticos. Los resultados demuestran un fuerte aporte metodológico de la metateoría a los estudios de la Organización del Conocimiento, así como un fuerte apoyo de la Diplomática a los estudios archivísticos.
\end{abstract}

Palabras clave: Diplomática. Metateoria. Identificación documental. Archivística. Documentos de archivo.

\section{Introdução}

As novas formas de produção documental, decorrente das novas tecnologias da informação e do aumento da complexidade burocrática nos sistemas administrativos, têm levado os profissionais da informação a encararem novos desafios no tocante à organização do conhecimento arquivístico.

Esse conhecimento, entendido como todo o conhecimento produzido por uma pessoa física ou jurídica e que está agrupado em um fundo documental, passa a ser produzido, portanto, em um contexto de constantes mudanças e rupturas paradigmáticas, o que leva os arquivistas a um repensar da teoria e dos métodos para organizar essa documentação.

\begin{abstract}
Since the 1980s Archival Science has faced new challenges regarding the organization of archival knowledge. In this way the concept of identification emerged as part of the record management processes. This process counts with the studies of contemporary diplomatics, once it aims to understand the records creation processes from the document analysis offered by the diplomatic method. This paper aims to present a new model for records identification, based on the diplomatic methods developed in 17th, 19th and XX centuries. Therefore, it counts with metatheory as a methodology for knowing and analyzing the diplomatic methods. The results show a strong methodological support of metatheory to the studies of Knowledge organization, as well as a strong support of Diplomatics to the archival studies.
\end{abstract}

Keywords: Diplomatics. Metatheory. Document identification. Archival science. Archival records.

Neste contexto nasce, na Espanha, no final dos anos 1980 , a função da identificação, no âmbito da gestão documental, como uma resposta às necessidades da formulação de metodologias para enfrentar os desafios colocados aos arquivos contemporâneos.

Entendida como a primeira fase do tratamento arquivístico, a identificação encontra na Diplomática, mais precisamente em seu método, a ferramenta necessária para a compreensão dos conjuntos documentais, a partir da uma análise do documento, podendo ser considerada parte da chamada "análise documental".

O método diplomático passa, portanto, a fundamentar a primeira etapa do tratamento arquivístico, entendida como a identificação do documento e de seu órgão produtor. 
Dessa maneira, o presente artigo apresenta um novo modelo de identificação do documento de arquivo - capaz de lidar com qualquer tipo de documentação, em qualquer contexto de produção e organização de documentos - a partir da análise e fusão dos métodos diplomáticos desenvolvidos entre os séculos XVII e XXI.

Para tanto, conta-se com os estudos metateóricos, enquanto metodologia para a criação de um novo modelo, chamado, aqui, de "idealizado", seguindo o conceito definido por Weber (1904) que o entende enquanto uma acentuação unilateral de um ou mais pontos de vista e pela síntese de um fenômeno individual concreto, difuso, discreto, mais ou menos presente e ocasionalmente ausente, que são arranjados de acordo com aqueles pontos de vista unilateralmente enfatizados e com uma construção analítica unificada.

\section{A identificação como função arquivística}

Com a explosão documental gerada após a Segunda Guerra Mundial, fez-se necessário estudar os documentos em seu nascimento, visando à racionalização da produção. Neste contexto, emergiu o conceito de gestão documental, que visa a controlar o documento desde o momento de sua produção até sua destinação final, qual seja, eliminação ou guarda permanente.

Segundo Rodrigues (2015) a gestão documental se caracteriza como um conjunto de procedimentos aplicados para controlar os documentos arquivísticos durante todo o seu ciclo de vida, incidindo sobre o momento da produção e acumulação na primeira e segunda idade, ou seja, nos arquivos correntes e intermediários. Ainda segundo a autora, a introdução de programas de gestão de documentos na teoria Arquivística, levou à necessidade da criação de metodologias para resolver os problemas observados nos arquivos.

Assim, nasce na Espanha, em 1980, o conceito da identificação como uma ferramenta para a análise do documento e de seu órgão produtor, aplicada às massas documentais acumuladas, visando à elaboração de propostas para a avaliação e classificação dos documentos de arquivo.

São dois os objetivos de estudo da identificação: órgão produtor e a tipologia documental, como destacou Rodrigues (2015, p. 72):

Trata-se de uma tarefa de pesquisa sobre os elementos que caracterizam os dois objetos de estudos da identificação: órgão produtor, analisando o elemento orgânico (estrutura administrativa) e o elemento funcional (competências, funções e atividades) e a tipologia documental, estudo que se realiza com base no reconhecimento dos elementos externos, que se referem à estrutura física, à forma de apresentação do documento (gênero, suporte, formato e forma) e internos.

É especificamente no tocante à tipologia documental, que a Diplomática Arquivística e seu método oferecem subsídios para sua análise. $\mathrm{O}$ método proposto pela Diplomática permite ao arquivista compreender os elementos internos e externos do documento de arquivo e as relações que eles guardam com o contexto.

\section{A metateoria enquanto ferramenta metodológica para a idealização de um modelo de identificação}

A metateoria tem sido amplamente utilizada no contexto da Ciência da Informação, principalmente no âmbito da Organização do Conhecimento, como demonstram os estudos de Vickery (1997), Svenonius (2004), Bates (2005) e Tennis (2008). Especificamente no contexto arquivístico, a Metateoria foi utilizada, primeiramente, por Tognoli (2014) como uma metodologia para melhor compreender a evolução da Diplomática desde o século XVII até o XXI. Entendida como a teoria sobre a teoria, a metateoria pode servir a quatro propósitos, segundo Ritzer (1991): (1) fornecer uma compreensão mais profunda do trabalho teórico existente (Mu); (2) fornecer uma perspectiva abrangente desse trabalho (Mo); (3) servir como um mecanismo para avaliação (Ma); e (4) servir como um prelúdio para um trabalho teórico futuro (Mp).

Ainda conforme Ritzer (1991), a partir da metateoria, há várias maneiras de se obter um conhecimento mais profundo e detalhado sobre a teoria da área de estudo, todas envolvendo uma dimensão interna/externa e intelectual/social. A interna se refere àquilo que existe dentro da área, que lhe é inerente, enquanto a externa se refere aos fenômenos que se encontram fora dela, mas que exercem algum impacto sobre a mesma. Por dimensão intelectual o autor entende tudo aquilo que se relaciona à estrutura cognitiva da área: teorias, ferramentas, ideias de outras disciplinas; por dimensão social entendese a estrutura sociológica da área, conforme demonstrado no esquema a seguir (Figura 1).

$\mathrm{Na}$ primeira abordagem (Interna-Intelectual), é possível verificar os paradigmas pelos quais passam as ciências, escolas de pensamento ou correntes teóricas unidas a partir das teorias da área estudada, bem como as ferramentas e métodos utilizados para analisar as teorias e os 
teóricos. A segunda (Interna-Social) foca os aspectos comuns entre as várias teorias da área, com ênfase em pequenos grupos de teóricos diretamente ligados e suas relações, bem como suas afiliações institucionais. A terceira (Externa-Intelectual) diz respeito aos conceitos, teorias e elementos emprestados de outras disciplinas, fazendo uso delas para analisar sua teoria. A quarta abordagem (Externa-Social) está diretamente ligada ao impacto da sociedade na construção da teoria.

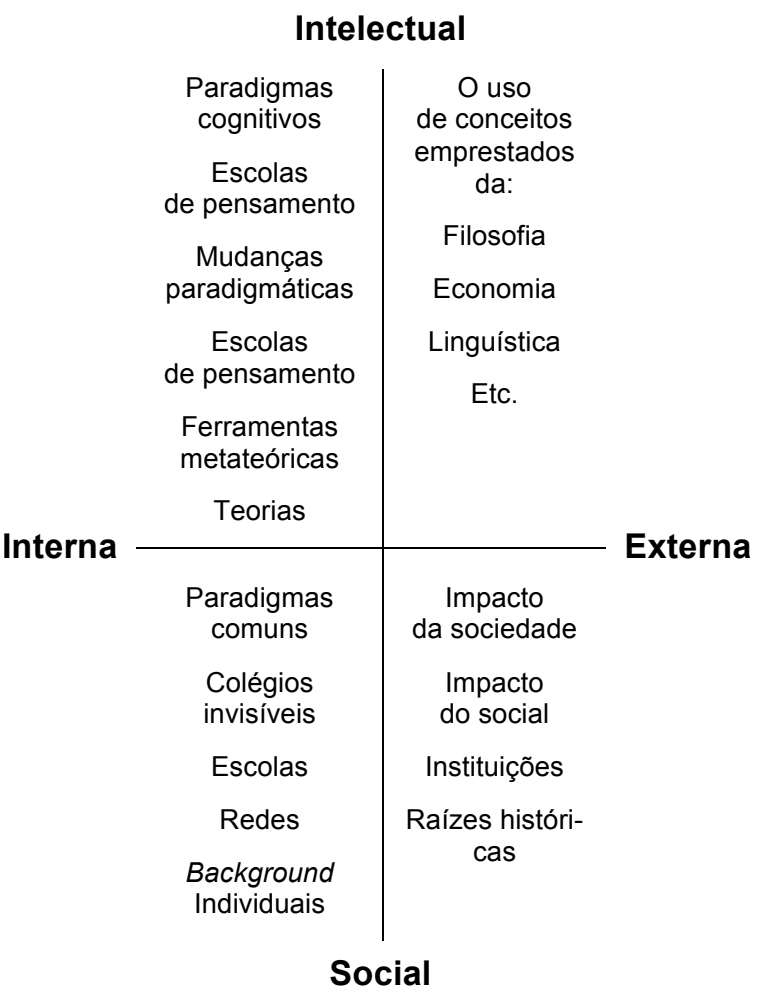

Figura 1. Principais tipos de $M u$

No entanto, é importante destacar que as abordagens não são excludentes, podendo-se encontrar os quatro tipos de $\mathrm{Mu}$ em um mesmo trabalho, como destacou Ritzer (1991):

Antes de proceder devo adicionar algumas notas cautelosas. Primeiro, as duas dimensões (internaexterna; intelectual-social) são uma continuação, sem linhas duras e estáticas entre seus polos. Segundo, os quatro tipos de $\mathrm{Mu}$ desenvolvidos ao transpassarem essas linhas não são rigidamente diferentes uns dos outros. Em outras palavras, em trabalhos metateóricos específicos, podem confluir dois, três, ou quatro tipos de Mu.

Com base nos estudos sobre o quadrante de Ritzer é possível concluir que o presente trabaIho encontra-se fundamentado na primeira abordagem do quadrante (Interna-Intelectual), uma vez que aprofunda questões inerentes à teoria e ao método da Diplomática para oferecer um estudo o mais detalhado possível, a partir das Escolas de pensamento, ou abordagens aqui previamente identificadas como Diplomática Clássica, Diplomática Moderna e Diplomática Contemporânea -, e de seus respectivos métodos, a fim de constituir um método para a identificação de documentos de arquivo baseado em um tipo ideal. Metateoria, portanto.

\section{A idealização de um modelo: o aporte da Diplomática à identificação dos documentos de arquivo}

A Diplomática esteve sempre em contato com os documentos de arquivo. Desde o século XVI, os documentos analisados sob a luz da Diplomática eram essencialmente documentos arquivísticos. Esses documentos eram evidências que comprovavam propriedades de terras, direitos e deveres de cidadãos e fatos que ocorriam no passado. Já nos primeiros tratados de Diplomática, é possível identificar capítulos dedicados exclusivamente aos arquivos, notadamente por ser este o lugar onde se encontravam os documentos analisados.

Embora a Diplomática e a Arquivística tenham trabalhado sempre com o mesmo objeto de estudo, o documento de arquivo, ambas só foram colocadas efetivamente em contato na década de 1960, quando Bautier (1962) estabeleceu as piéces d'archives enquanto objeto de estudo da Diplomática, em resposta à chamada "crise diplomática" sugerida por alguns autores, na época, em decorrência de um exaurimento vivenciado pela disciplina no século $X X$.

Até 1960 o objeto de estudo da Diplomática estava ligado ao estudo da forma de documentos de natureza estritamente jurídica. A partir do discurso de Bautier, qualquer documento de arquivo, independente de sua natureza, época ou forma, passa a ser passível de análise pelo método diplomático.

No entanto, ao longo dos séculos, o método diplomático sofreu modificações, ao passo que os documentos se modificaram, assim como o sistema jurídico no qual são criados. Neste sentido, para a idealização de um modelo ideal de análise para a identificação dos documentos de arquivo, faz-se necessário abordar os métodos que sustentaram a disciplina nos últimos quatro séculos.

As primeiras formulações para a enunciação de um método surgiram na França, em 1681, com a publicação do tratado De re diplomática, de Jean Mabillon, que busca verificar a autenticidade de diplomas mantidos nos arquivos de 
ordens religiosas. Confrontando e analisando diplomas inseridos em uma série cronológica ou em um conjunto específico de documentos de uma determinada época ou lugar, Mabillon cria um "método" histórico, analítico-comparativo que sustenta o estudo crítico dos documentos até os dias de hoje.

Seus elementos eram confrontados e analisados com base em um contexto pré-estabelecido. Para tanto, Mabillon (1681) definiu-os como caracteres intrínsecos e extrínsecos, descrevendo os primeiros como o conteúdo do documento que abrange, por sua vez, o estilo, o texto, os selos, a data e as assinaturas. Os caracteres extrínsecos compreendiam o material (matéria) sobre o qual eram escritos os documentos (pergaminho, papiro, tábuas de argila, chumbo, pedras) e o meio usado para inserir as escrituras ou símbolos nesse material (tinta).

Essas formulações podem ser consideradas o embrião do método diplomático que só foi efetivamente construído no século XVIII, na Áustria, por Theodor Von Sickel.

O autor mantém a divisão do documento em elementos internos e externos, aprofundandoos. Assim, os elementos externos são o material, os tipos de escritura, os selos e abreviaturas, e os comentários. Já os elementos internos apresentam uma evolução ao serem divididos em texto e protocolos, além da língua. Dessa forma, o conteúdo do documento é dividido em protocolo inicial, que engloba invocação e nome e título do autor; texto, englobando preâmbulo, nome e título do destinatário, exposição, dispositivo, corroboração e anúncio dos sinais de validação. O protocolo final, ou escatocolo é dividido em assinatura, datas e precação.

Os protocolos funcionam, portanto, como a moldura do documento. Eles são responsáveis por abrir e fechar o teor documental, e às vezes manterão a mesma fórmula quando se trata de um mesmo autor ou de um mesmo ato jurídico. Seu principal ofício dentro da estrutura do documento diplomático é fornecer os elementos de validade legal. Já o teor documental, ou o texto propriamente dito, traz o conteúdo que pode variar segundo a natureza do ato jurídico.

Vale dizer que ambos os métodos eram utilizados estritamente para verificar a autenticidade dos diplomas da Idade Média, de natureza estritamente jurídica, fosse para fins prático-jurídicos ou históricos.

A abertura do objeto de estudo da Diplomática a todos os documentos de arquivo, por Bautier, permitiu sua aproximação à Arquivística, dando origem, no final do século $X X$, a uma nova abordagem que, baseando-se nos métodos aqui expostos, incorpora novos elementos para a análise dos documentos de arquivo.

Assim, o método proposto pela chamada Diplomática Arquivística, ou Diplomática Contemporânea, que tem como representante mais expressiva Luciana Duranti, recebe incorporações de novos elementos, criando um método à parte, com base naqueles propostos por Mabillon e Ficker, mas que pudesse ser aplicado aos documentos contemporâneos, principalmente àqueles gerados eletronicamente. Esse método mantém a divisão proposta por Mabillon, dos elementos internos e externos, e aquela proposta por Sickel, sobre os protocolos e texto. Assim, os elementos externos englobam meio, escrita, linguagem, sinais especiais e selos; enquanto os elementos internos englobam protocolo inicial, dividido em timbre, título do documento, datas, invocação, subscrição, inscrição, saudação, assunto, formula perpetuitatis e precação; o texto, dividido em preâmbulo, notificação, exposição, dispositivo e cláusulas finais e protocolo final dividido em corroboração, datas, precação, cláusula complementar, atestação, qualificação das assinaturas e notas secretariais.

Esse método sustenta, hoje, os estudos da Tipologia Documental e pode ser utilizado para a compreensão do contexto de criação dos documentos quando não é possível o conhecimento de outras fontes auxiliares para tanto. Ou seja, quando o arquivista não tem acesso ao organograma ou regimento interno da instituição, seu estudo pode partir diretamente do documento com o auxílio da análise diplomática. Dessa forma, a análise parte do documento e de suas partes para o fundo.

No entanto, alguns elementos devem ser incorporados ao método "contemporâneo", para que ele possa ser efetivo na identificação dos documentos de arquivo.

Neste sentido, propõe-se, aqui, um tipo ideal de método diplomático, capaz de lidar com a documentação arquivística em seus mais diversos suportes, auxiliando o arquivista no momento da identificação dos documentos, bem como das funções e atividades que o geraram.

Especificamente no contexto deste artigo, entende-se por "tipo ideal" de método diplomático aquele formado a partir das formulações e dos métodos diplomáticos aqui apresentados, que funcione como uma síntese, arranjado com base nos elementos utilizáveis para analisar a forma de qualquer documento, em qualquer época, formando uma construção analítica unificada. 
Nesse sentido, apresentam-se, a seguir, os elementos externos e internos da forma documental que devem ser considerados na crítica diplomática "ideal":

\begin{tabular}{ll}
\hline Elementos externos & Elementos Internos \\
\hline Material & Língua \\
Tipo de escrita & Estilo de linguagem \\
Qualidade de impressão & Protocolo Inicial \\
Meio de registro & Involo/assunto/datas/ \\
Selos e Sinais & nome e predicado do \\
& autor e destinatário/ \\
& saudação inicial) \\
& Texto \\
& (preâmbulo/exposição/ \\
& notificação/dispositivo/ \\
& sanção/corroboração/ \\
& anúncio dos sinais \\
& de validação) \\
& Protocolo Final \\
& (precação/saudação \\
& final/datas/subscrição) \\
\hline
\end{tabular}

Quadro 1. Elementos externos e internos da crítica diplomática ideal

Nos elementos externos, encontra-se o material, dividido em suporte (livro, pedra, tábuas de argila, disco rígido) e formato ( $\mathrm{A} 4$, carta, impresso, digital). Os tipos de escrita compreendem aquelas hieroglíficas, cuneiformes, românicas, arábicas, góticas, etc. A qualidade de impressão visa a oferecer um melhor detalhamento das condições físicas do documento, analisando se ele possui rasuras ou deteriorações, por exemplo. Os meios de registro podem ser as tintas utilizadas quando se usa uma caneta, ou máquina de escrever, ou o software quando se trata de documentos eletrônicos. Os selos e sinais são considerados, aqui, como elementos externos por terem sido colocados após a feitura do documento, como os carimbos de autenticação, ou o registro de protocolo e número de classificação no arquivo, ou assinaturas eletrônicas, por exemplo.

Os elementos internos apresentam poucas variações com relação aos demais elementos das formulações analisadas. Aqui, a língua é o idioma no qual o documento é redigido, enquanto o estilo pode ser formal ou informal. A divisão entre texto e protocolos mantém-se, apresentando apenas algumas variações, como a inserção das datas e da saudação, tanto no protocolo inicial quanto no protocolo final. Inserem-se no protocolo inicial o assunto e o título do documento, e a titulação engloba tanto o autor e seu predicado, quanto o destinatário do documento.

Entende-se, para a idealização do método, a participação de pelo menos três pessoas na formação do documento: autor (da ação/do documento), destinatário (da ação/do documento) e escritor (responsável pelo teor e pela articulação do texto). No entanto, vale ressaltar que todos devem estar respaldados nos conceitos de competência e responsabilidade para criar/redigir $o$ ato.

Nesse contexto, após definir os elementos externos e internos para a análise do documento e as pessoas que contribuem para sua formação, apresenta-se, no quadro a seguir, a síntese do método diplomático idealizado:

\section{Espécie documental}

Tipo documental

Categoria Documental:

Dispositivo

Probatório

Informativo

Natureza do ato:

Público

Privado

Elementos externos:

Material

Tipo de escrita

Qualidade de impressão (visualização,

integridade do documento)

Meio de registro

Selos e Sinais

Elementos internos:
Língua
Estilo de linguagem
Protocolo Inicial
(Título/Assunto/Datas/Invocação/Titulação
nome e predicado do autor e destinatário/
Saudação inicial)
Texto
(preâmbulo /exposição/notificação/dispositivo/sanção/
corroboração/ anúncio dos sinais de validação)
Protocolo Final
(precação/Saudação final/datas/subscrição)

Pessoas envolvidas na criação do documento:

Autor da ação

Autor do documento

Destinatário da ação

Destinatário do documento

Escritor

Testemunhas envolvidas

\section{Estado de transmissão:}

Pré-original

Original

Pós-original 
Informações complementares:

Fundo produtor/recebedor

Grupo

Série

Notação

Quadro 2. Método diplomático idealizado

No método proposto, o primeiro elemento a ser identificado é a espécie documental, ou seja, o veículo redacional escolhido para o registro da ação. Segundo Camargo \& Bellotto (1996), a espécie é a configuração que assume um documento de acordo com a disposição e natureza das informações nele contidas. Assim, a primeira coisa que o profissional da informação deve saber é qual é esse veículo, pois ele será determinante para o estudo da forma. Um exemplo de espécie que engloba tanto os documentos antigos quanto os contemporâneos é a "escritura".

O segundo elemento, o tipo documental, é a espécie agregada da atividade que irá gerar o

documento, ou seja, seguindo o exemplo acima, quando se tem uma escritura de transação imobiliária, a "compra e venda de imóvel" corresponderá à atividade de registrar o ato de comprar e vender imóvel, e a escritura é o veículo redacional eleito e juridicamente válido para a inserção desse ato.

Em seguida é identificada a categoria documental, que diz respeito ao valor jurídico do conteúdo dos documentos. Desta feita, o documento dispositivo é aquele que nasce para fazer cumprir e dar validade à ação, enquanto o documento probatório simplesmente atesta um fato jurídico já completo, válido perfeitamente antes de sua documentação. Por último, o documento informativo esclarece as questões e/ou informações contidas em outros documentos.

A natureza do ato também é importante no momento da crítica diplomática, uma vez que determina a relação entre documento e autor. Para fins de esclarecimento, no método ideal, um documento é considerado público quando criado por uma pessoa pública, ou em seu nome, exercendo uma atividade jurídica no contexto público. Ao contrário, um documento é privado se criado por uma pessoa privada, ou em seu nome, no sistema jurídico no qual atua.

A identificação das pessoas envolvidas na criação do documento é fundamental uma vez elas são os sujeitos de deveres e direitos envolvidos no sistema jurídico no qual o documento é criado. Ao identificar os autores, destinatários, escritor e testemunhas, evidenciam-se justamente as relações entre elas e o sistema jurídico no qual atuam, fornecendo um estudo mais deta-
Ihado do contexto de criação desses documentos.

O estado de transmissão determina o grau de autoridade do documento que está sendo analisado e, por essa razão, sua identificação é primordial na crítica diplomática. O documento original terá valor e peso muito maiores do que o rascunho ou cópia, por exemplo, por ser o primeiro e perfeito.

Por último, as informações complementares funcionam no contexto arquivístico, uma vez que é possível identificar os fundos/grupos/ séries aos quais pertence o documento, assim como o código de classificação ou número de registro de protocolo, caso existam.

Logo, com base em um tipo ideal de método diplomático, seria possível analisar tanto os documentos antigos, quanto os documentos contemporâneos, uma vez que apresenta elementos comuns a todos os métodos analisados aqui, sem limitar cronologicamente o objeto de análise da Diplomática. Em adição, são incorporados alguns elementos da análise tipológica como o estudo do fundo, espécie e tipo documental -, permitindo ao arquivista fazer uso do método sem maiores complicações e elementos desnecessários.

Considerando o método analisado enquanto estrutura ideal, seguindo o conceito weberiano de tipo ideal, propõe-se, aqui, ainda, um resumo desse método, que contemple tão somente os elementos necessários à análise dos documentos arquivísticos, excluindo, portanto, alguns elementos significativos somente à análise diplomática com o objetivo puramente de verificação da autenticidade dos documentos. Assim, apresenta-se, a seguir, o método para a identificação dos documentos de arquivo (Quadro 3).

Espécie documental:

Tipo documental

Categoria Documental:

Dispositivo

Probatório

Informativo

Natureza do ato:

Público

Privado

Elementos externos:

Material

Meio de registro 
Elementos internos:

Protocolo Inicial (Título/Assunto/Datas/

Titulação - nome e predicado do autor e destinatário)

Texto (dispositivo)

Protocolo Final (datas/subscrição)

Pessoas envolvidas na criação do documento:

Autor da ação

Autor do documento

Destinatário da ação

Destinatário do documento

Escritor

Estado de transmissão:

Pré-original

Original

Pós-original

Informações complementares:

Fundo produtor/recebedor

Grupo

Série

Notação

Quadro 3. Método para a identificação de documentos de arquivo

O método proposto oferece ao arquivista uma ferramenta para identificar as informações necessárias à reconstrução do contexto arquivísti$\mathrm{co}$, tendo como base o próprio conjunto documental. Tal método poderá funcionar como base metodológica para a identificação dos tipos documentais na constituição das séries no momento da identificação. Logo, o método seria eficiente na segunda fase da identificação, ou seja, no momento do estabelecimento das tipologias documentais.

\section{Considerações}

Buscou-se, neste artigo, apresentar uma nova ferramenta para a análise dos conjuntos documentais contemporâneos, no contexto da Arquivística. Neste sentido, a base metodológica oferecida pela Diplomática, permitiu uma aproximação de ambas as disciplinas a partir da década de 1960. Desde então, a Diplomática vem subsidiando o trabalho arquivístico no tocante à análise documental, quando o profissional da informação parte especificamente da identificação do documento, enquanto um dos objetos de estudo da identificação dos conjuntos documentais e do contexto de produção.

Para a construção dessa nova ferramenta metodológica, contou-se com os estudos metateóricos de Ritzer e com o conceito de tipo ideal formulado por Weber. Assim, os estudos de Ritzer nos permitiu enxergar o percurso histórico e conceitual trilhado pela Diplomática, bem como a evolução e constituição de seu método de análise documental. Da mesma maneira, o con- ceito de tipo ideal de Weber, nos permitiu, após a análise metateórica, formular um método com base em todos os outros estudados, e considerá-lo ideal para analisar a documentação contemporânea.

É importante destacar, ainda, que, embora o método de análise proposto seja apenas idealizado, ele pode contribuir como uma ferramenta didática ao ensino da Diplomática Contemporânea nos cursos de Arquivologia, uma vez que fornece os elementos de análise para todos os documentos, de uma maneira mais clara e simplificada, além de imediata.

Dessa forma, abre-se espaço para os estudos posteriores que possam se dedicar à análise do "método ideal" ora proposto, às novas tipologias documentais que são constantemente criadas no universo documental, fortemente permeado pelos avanços tecnológicos.

\section{Referências}

Bates, Marcia (2005). An introduction to metatehories, theories, and models.// Fischer Karen; Erdelez, Sandra; Mckechnie, Lynne (Eds). Theories of information behavior. Medford: Information Today, 2005, 1-24.

Bautier, Robert-Henri (1961). Leçon d'ouverture du cours de diplomatique à L'Ecole des chartes. // Bibliothèque de l'Ecole des Chartes. 1961. 194-225.

Camargo, Ana Maria de Almeida; Bellotto, Heloísa Liberalli (1996). Dicionário de Terminologia Arquivística. São Paulo: Secretaria da Cultura, 1996.

Mabillon, Jean (1681) De re diplomatica libri sex. 1681. Paris.

Ritzer, George (1991). Metatheorizing in Sociology. Lexington: Lexignton Books, 1991.

Rodrigues, Ana Célia (2015). Identificação como requisito metodológico para a gestão de documentos e acesso a informações na administração pública brasileira. // Ciência da Informação. 42:1(2015) 64-80.

Sickel, Theodor Von (1867). Acta regum er imperatorum Karolinorum digesta et enarrata. Wien: Duck und Verlag Von Carl Gerold's Sohn, 1867.

Svenonius, Elaine (2004). The epistemological foundations of knowledge representation. // Library Trends. 52:03 (Winter, 2004) 571-587.

Tennis, Joseph T (2008). Epistemology, Theory, and Methodology in Knowledge Organization: toward a classification, metatheory, and research framework. // Knowledge Organization. 35:2 (2008)102-112.

Tognoli, Natália Bolfarini (2013). A construção teórica da Diplomática: em busca de uma sistematização de seus marcos teóricos como subsídio aos estudos arquivísticos. Tese (doutorado). Programa de Pós-Graduação em Ciência da Informação - Faculdade de Filosofia e Ciências, Unesp, Marília, 2013.

Weber, Max (1904). Objectivity in Social Science and Social Policy. // Shils, E. A.; Finch, H.A. (Eds). The Methodology of the Social Sciences. New York: Free Press, 1949. 77128.

Enviado: 2015-05-01. Segunda versión: 2015-09-01. Aceptado: 2015-09-01. 
